\title{
Seduepb
}

\section{A comunicação de massa no campo da antropologia}

\author{
Isabel Travancas \\ Silvia Garcia Nogueira
}

\section{SciELO Books / SciELO Livros / SciELO Libros}

TRAVANCAS, I., and NOGUEIRA, SG., orgs. A comunicação de massa no campo da antropologia. In: Antropologia da comunicação de massa [online]. Campina Grande: EDUEPB, 2016. Paradigmas da Comunicação collection, pp. 9-25. ISBN 978-85-7879-332-6. Available from SciELO Books $<\underline{\text { http://books.scielo.org }>\text {. }}$

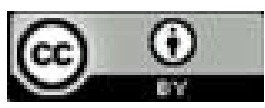

All the contents of this work, except where otherwise noted, is licensed under a Creative Commons Attribution $\underline{4.0 \text { International license. }}$

Todo o conteúdo deste trabalho, exceto quando houver ressalva, é publicado sob a licença Creative Commons Atribição 4.0.

Todo el contenido de esta obra, excepto donde se indique lo contrario, está bajo licencia de la licencia $\underline{\text { Creative }}$ Commons Reconocimento 4.0. 


\section{A Comunicação de Massa no campo da Antropologia}

Isabel Travancas

Silvia Garcia Nogueira

\section{Introdução}

Há mais de dez anos, quando começaram a surgir os primeiros Grupos de Trabalho ou Seminários Temáticos sobre Comunicação de Massa nos Congressos da área de Ciências Sociais, mais especialmente na Antropologia, não se poderia imaginar o quanto esse campo iria crescer e ser uma presença nos eventos futuros. E é um pouco sobre essa história que gostaríamos de falar.

A grande referência para os estudos sobre a Indústria Cultural e os meios de comunicação de massa, durante muito tempo, foram os trabalhos da chamada Escola de Frankfurt, especialmente a obra de Theodor Adorno, Max Horkheimer e Walter Benjamin. Eles não só produziram uma reflexão original sobre essa indústria e seus produtos como deram a ela um status de objeto legítimo de pesquisa. Adorno e Horkheimer (1991) com seu texto clássico "A Indústria Cultural: o esclarecimento como mistificação das massas" estavam preocupados em entender como a cultura tinha se transformado 
em produto e todos eram forçados a passar pelo filtro da indústria cultural. Nela, não há lugar, segundo eles, para a crítica nem para o respeito. Uma visão bastante radical, classificada como "apocalíptica” por Umberto Eco (1998), em seu também importante ensaio sobre a indústria cultural. Essas fontes foram essenciais para a construção de um espaço de reflexão sobre os meios de comunicação de massa dentro da Antropologia.

A Escola de Chicago, com seus estudos sobre a cidade, seus habitantes e seus estilos de vida foi outra corrente fundamental por olhar a questão urbana sob um novo prisma e demonstrar que a Antropologia não precisava apenas estudar povos exóticos e distantes. O trabalho de Robert Park (2008, p.51-70) é relevante não só pelo fato de ele ter sido jornalista e enfatizado a influência dessa experiência na sua formação, mas por procurar ver "as notícias como forma de conhecimento" destacando inclusive que "no mundo moderno o papel da notícia tem assumido maior importância em comparação com outras formas de conhecimento, a história, por exemplo" (PARK, 2008, p.70). E para o autor, o surgimento do repórter pode ser considerado um dos mais importantes eventos da sociedade norte-americana.

Dentro de um contexto mais contemporâneo de reflexão sobre os meios de comunicação de massa, os trabalhos de duas antropólogas norte-americanas se destacam. São elas Debra Spitulnik e Lila Abu-Lughod.

Spitulnik é professora da Emory University e escreveu uma tese de doutorado sobre a rádio na África. Sua resenha sobre a interseção da Antropologia com a Comunicação, publicada em 1993, no Annual Review of Anthropology, chama a atenção para o fato de ainda, naquela época, não ser possível falar em uma "antropologia dos meios de comunicação de massa”, embora, na última década, tenha havido um aumento do interesse em estudá-los. Segundo a 
antropóloga, há inúmeras maneiras de se abordar antropologicamente os meios de comunicação de massa: como instituições, como lugares, como práticas comunicativas, como produtos culturais, como atividades sociais, como formas estéticas e como desenvolvimentos históricos.

Abu-Lughod é professora da Columbia University e vem estudando questões de gênero, cultura e política no contexto da sociedade egípcia. Ela é uma dos organizadores do livro Media worlds: anthropology on new terrain (2002), junto com Faye Ginsburg e Brian Larkin, publicado em 2002 e ainda inédito no Brasil. Ele reúne 20 artigos sobre a comunicação de massa sob diversas perspectivas, produtos e países. Spitulnik é autora de um dos textos desta coletânea onde aborda sua pesquisa etnográfica sobre rádio na Zâmbia. Abu-Lughod também realizou uma pesquisa etnográfica sobre a recepção de televisão no Egito (2001) onde discute a interpretação dos personagens e das narrativas produzidas pela televisão norte-americana pelas mulheres nativas.

No Brasil, um dos trabalhos pioneiros sobre comunicação dentro do campo antropológico é a pesquisa sobre televisão da antropóloga Ondina Leal (1986). Em A leitura social da novela das oito, a autora estabelece um diálogo com os pensadores da Escola de Frankfurt e com os teóricos da comunicação, para entender o lugar e o papel da televisão, especialmente da novela das oito, na sociedade brasileira. Para isso, selecionou dois grupos de famílias para juntos assistirem à novela. $\mathrm{O}$ primeiro era formado por pessoas das classes populares e o outro por pessoas de camadas médias intelectualizadas. Ambos residentes na cidade de Porto Alegre. Ela percebeu que o significado simbólico da televisão era muito distinto nas duas famílias.

No âmbito da publicidade e do consumo, as pesquisas de Everardo Rocha $(1985,1995)$ foram uma novidade em termos de 
tema e abordagem. Na primeira, estudou os publicitários e analisou anúncios buscando entender a lógica da produção publicitária e seus significados. Em sua tese de doutorado procurou discutir as correntes que problematizaram os meios de comunicação de massa e investigar o lugar da publicidade na sociedade contemporânea.

Isabel Travancas desenvolveu em sua dissertação de mestrado uma pesquisa sobre carreira e identidade entre jornalistas (1993). Seu objetivo foi entender como se constitui a identidade deste profissional a partir de uma etnografia e de entrevistas com cerca de 50 jornalistas da imprensa carioca. Silvia Nogueira e Candice Vidal também escolheram o jornalismo e os jornalistas como objeto de investigação. A primeira realizando uma etnografia da redação de dois grandes jornais do Rio de Janeiro e a segunda fazendo uma análise da figura do repórter a partir das matérias do Prêmio Esso.

Esses são alguns trabalhos das décadas de 1980 e 1990 que podem ser considerados uns dos primeiros dentro dessa temática da antropologia da comunicação de massa no Brasil. De lá para cá, o campo cresceu e se ampliou. E um dos lugares para reflexão mais fecunda foram os congressos da área.

Em 2001, no XXV Encontro Anual da ANPOCS, realizado em Caxambu, Isabel Travancas coordenou com Patrícia Farias o Seminário Temático "Antropologia e comunicação”. Ele reuniu trabalhos sobre jornalismo, cinema, televisão, música e publicidade. Foi sem dúvida um dos primeiros congressos da área a ter um núcleo de discussão específico sobre meios de comunicação de massa. Uma parte destes artigos foi reunida no livro de mesmo título publicado em 2003.

Na 23a Reunião Brasileira de Antropologia (RBA), ocorrida em Gramado, Rio Grande do Sul, em junho de 2002, juntamente com Patrícia Farias, Isabel Travancas organizou uma mesa de Comunicações Coordenadas "Antropologia e comunicação" onde 
foram apresentados seis trabalhos sobre figuras públicas e o papel da mídia na sua construção, telenovelas, publicidade, imprensa e música. Foi uma tentativa de continuar levando o tema da comunicação de massa para os encontros da Associação Brasileira de Antropologia (ABA).

Em 2004, foi organizado pelos professores Peter Fry e Esther Hamburguer o Fórum de Pesquisa "Mercado, consumo e mídia: disputas por representações" na 24a RBA, realizada em Recife, Pernambuco, em junho. Neste encontro, o foco não foi apenas a questão da comunicação de massa, mas sua perspectiva de consumo e mercado. Dos 24 trabalhos apresentados, as principais temáticas foram: consumo, circulação de mercadorias, propaganda, moda, televisão e representações da mídia, em especial dos jornais.

No $25^{\circ}$ encontro da $A B A$, em 2006, não houve nenhum Grupo de Trabalho ou Seminário sobre comunicação de massa sob o olhar antropológico. Isso veio a acontecer na reunião de 2008, em Porto Seguro, Bahia, quando Isabel Travancas e Nara Magalhães coordenaram o Grupo de Trabalho "Diferenças e desigualdades na mídia: um olhar antropológico". Compuseram o GT 14 trabalhos e cinco painéis distribuídos em três sessões cujos temas foram: a representação da diferença na televisão, uma antropologia da mídia e imprensa, televisão, violência e consumo. A televisão foi, sem dúvida, o tema preponderante dos trabalhos e abordada de diversas formas. Estudos empíricos e teóricos, análises de programa e de receptores demonstrando que seu lugar vem crescendo também no contexto acadêmico e em particular no campo da antropologia.

Belém, no Pará, foi a cidade da $27^{a}$ Reunião Brasileira de Antropologia, realizada de 1 a 4 de agosto de 2010. Nesta reunião, Isabel Travancas com o antropólogo português e pesquisador do Instituto Universitário de Lisboa (ISCTE) Filipe Reis coordenaram o Grupo de Trabalho "Antropologia e meios de comunicação", 
cujo título foi inspirado no artigo de Debra Spitulnik (1993) "Anthropology and mass media". O grupo congregou 16 comunicações e cinco posters. Os autores dos trabalhos eram brasileiros, ainda que dois portugueses selecionados não tenham podido comparecer. A discussão e a temática da primeira mesa foram a metodologia de trabalho em pesquisas sobre comunicação. Já a segunda mesa versou sobre os trabalhos etnográficos sobre a imprensa no Brasil e em Portugal, e a produção e a recepção midiática em diferentes países foram discutidas na última sessão.

Além das reuniões da $\mathrm{ABA}$, aconteceram diversos eventos regionais destinados às regiões Norte e Nordeste denominados ABANNE. No ano de 2003, Patrícia Farias e Isabel Travancas coordenaram o Grupo de Trabalho denominado "Antropologia e comunicação" com 29 trabalhos distribuídos em seis sessões com os seguintes assuntos sendo discutidos: consumo e marketing, cinema e vídeo, música, televisão, mídia impressa e rádio e internet. Naquele momento, houve uma presença considerável de trabalhos sobre consumo, marketing e propaganda, uma vez que ainda eram raros os grupos dedicados a esses temas. A música também tem aparecido de forma cada vez mais eventual na medida em que há outros espaços de discussão para ela nos congressos. Os autores dos trabalhos não estavam restritos ao universo regional do Norte e Nordeste, havendo pesquisadores de todas as partes do país.

Na ABANNE realizada em Natal, Rio Grande do Norte, em agosto de 2009, Silvia Nogueira e Isabel Travancas foram as responsáveis pelo Grupo de Trabalho "Antropologia e comunicação" que consistiu em três mesas sobre: etnografias da comunicação, publicidade e direitos humanos e comunicação. $\mathrm{O}$ tema desta última estava estreitamente ligado à temática mais geral do encontro que foi “Direitos, Justiça e diferença na América Latina”. 
A última RBA, realizada na PUC de São Paulo em julho de 2012, contou com o Grupo de Trabalho "Antropologia da comunicação de massa” coordenado por Silvia Nogueira e Isabel Travancas. Neste grupo, foram apresentados 18 trabalhos de pesquisadores em distintos momentos da carreira, portanto, havia mestrandos, mestres, doutorandos e doutores, além de graduando escrevendo junto com mestres ou doutores os textos.

A diversidade regional foi outro ponto de destaque, não havendo apenas antropólogos da região Sudeste. Ao contrário, havia participantes de todas as regiões do país. Nem todos tinham formação em Antropologia. Gente de Letras e de Comunicação também fez parte do GT. As quatro mesas abordaram os seguintes temas: televisão, imprensa e mercado editorial, política e cinema e, a última, publicidade e consumo.

Como temos percebido, ao longo destes mais de 10 anos de participação em congressos, televisão continua sendo um tema muito relevante e segue despertando o interesse dos pesquisadores. Imprensa é outro assunto sempre presente nos grupos. Um tema que nem sempre é discutido dentro de uma perspectiva de uma Antropologia da Comunicação de Massa é o cinema, pois comumente faz parte do conjunto de pesquisas no campo da Antropologia Visual. A política sempre perpassa as discussões sobre os meios de comunicação, algumas vezes de forma mais genérica e outras, mais específica, como foi o caso deste grupo de 2012. Um assunto que raramente apareceu foi o mercado editorial e os livros de maneira geral. Algumas das exceções foram as pesquisas de Isabel Travancas. A primeira - sua tese de doutorado - foi apresentada no Seminário Temático da Associação Nacional de Pós-Graduação e Pesquisa em Ciências Sociais (ANPOCS) de 2001 com o título "O livro no jornal" e a segunda, a comunicação "O livro como objeto da mídia", compôs a programação do Grupo de Trabalho na Reunião de 
Antropologia do Mercosul (RAM) de 2011, sobre a qual falaremos em seguida.

Um detalhe importante nesta tentativa de mapear a presença da discussão sobre os meios de comunicação no campo da Antropologia corresponde às transformações sofridas pelos títulos dos GTs. Eles começam de forma mais aberta e depois passam a unir os dois campos - Antropologia e Comunicação -, até que, no último congresso, já se postulou uma Antropologia da Comunicação de Massa. Este título procura precisar o objetivo e o enfoque das pesquisas.

Além destes encontros nacionais bienais da $\mathrm{ABA}$ e dos encontros regionais, um congresso de Antropologia da América Latina vem crescendo a cada evento. Trata-se da Reunião de Antropologia do MERCOSUL - RAM - iniciada em 1995. Ela vem sendo realizada de dois em dois anos, na Argentina, no Brasil e no Uruguai.

Em julho de 2007, na VII Reunião de Antropologia do Mercosul sediada na Universidade Federal do Rio Grande do Sul (UFRGS), em Porto Alegre, os antropólogos Nara Magalhães e Sergio Caggiano - este último argentino e professor da Universidad de Buenos Aires e da Universidad de La Plata - organizaram o Grupo de Trabalho "Antropólogos e as interpretações de interpretações da mídia”. Foram discutidos os temas de gênero na mídia, do "Outro" e suas representações midiáticas e do consumo e da cultura popular e da cultura massiva em três sessões com apresentação de 18 dos 28 previstos. Por ser um evento internacional, havia pesquisadores de várias nacionalidades.

Na RAM seguinte, de 2009, na qual Buenos Aires foi a sede, quatro antropólogos - dois argentinos Maria Graciela Rodriguez e Sergio Cagginano e duas brasileiras, Isabel Travancas e Nara Magalhães - lançaram a proposta do Grupo "Antropología y comunicación”. Este GT recebeu mais de 70 resumos de autores de 
diversas nacionalidades. Foram selecionadas 37 comunicações, divididas em cinco sessões. A construção da representação de grupos diversos em diferentes mídias (imprensa, televisão, publicidade e rádio) foi um dos pontos mais abordados no conjunto dos trabalhos, assim como a internet apareceu como objeto de pesquisa através de estudos sobre lan houses e sobre as apropriações das classes populares desta nova mídia.

Na última RAM, realizada em Curitiba em 2011, Isabel Travancas e a antropóloga argentina Patrícia Fasano foram responsáveis pelo Grupo de Trabalho "Antropologia da comunicação". Seu objetivo foi reunir a maior gama possível de pesquisas antropológicas sobre a comunicação de massa produzidas nos países do MERCOSUL. Além de possibilitar uma discussão sobre os trabalhos, a intenção era refletir sobre os mesmos em uma perspectiva comparativa. Foram organizadas três sessões intituladas: "A construção da identidade na mídia: jovens e leitores, populações de fronteira e grupos indígenas", "A televisão em debate: identidade e consumo" e "Moda, gênero, saúde e política e suas representações midiáticas". Os 26 trabalhos que compuseram o grupo, entre seis painéis e 20 comunicações tiveram uma amplitude grande de temas. Mais uma vez, a televisão ocupou um lugar importante, seguida pela imprensa escrita. Pela primeira vez, o livro e seus leitores foram objeto de dois trabalhos.

Cabe dizer ainda que ao longo dos anos, desde que surgiram os primeiros GTs e similares sobre Antropologia e Comunicação, alguns dos autores presentes neste livro participaram de suas discussões de diferentes formas: como debatedores, apresentadores de comunicação oral e/ou ouvintes. Este é o caso particular de Ana Lucia Enne, Carla Barros e Silvia Nogueira, além de Isabel Travancas, que acompanharam mais de perto o desenvolvimento do campo. Nessa trajetória, ainda, foi possível perceber pessoas em 
diferentes níveis na hierarquia acadêmica se incorporando ao grupo: professores, doutorandos que viraram doutores e mestrandos que viraram mestres de um evento para outro. Assim, fazem parte desta coletânea pessoas que participaram mais de uma vez dos congressos citados, como Luciana de Oliveira, Jimena Massa e Lennita Ruggi, e pesquisadores que estão se aproximando da temática, como Julia Schnorr, Jeana Santos, Talita Castro, Janie Pacheco, César Cundari da Rocha Santos, Marcelo Francisco e Mercedes Calzado.

Este livro reúne 11 artigos apresentados no Grupo de Trabalho "Antropologia da comunicação de massa" da $28^{a}$ Reunião Brasileira de Antropologia, realizada na PUC de São Paulo de 2 a 5 de julho de 2012. Foram enviados para as organizadoras mais de 50 trabalhos e 18 selecionados para compor quatro mesas de temas variados. A primeira tratou da televisão, sua representação e recepção. A segunda foi sobre as narrativas da mídia e abordou o mercado editorial, a crônica e a imprensa em diferentes contextos. Política e cinema foram os temas centrais da terceira mesa e publicidade e consumo os da última.

Carla Barros vem estudando as empregadas domésticas desde seu doutorado em Administração na Coppead quando analisou o consumo de empregadas e sua relação com as patroas. No texto deste livro, ela segue investigando o mesmo grupo profissional e suas relações de consumo através do seriado A Diarista, da TV Globo, exibido entre 2004 e 2007. A seu ver, o cotidiano da diarista Marinete está muito marcado pela "carência material" e quando a protagonista tenta consumir o mesmo que os patrões é penalizada. Ao longo do programa, a protagonista se coloca como uma espécie de mediadora entre dois mundos: o dos "pobres" e o dos 
"ricos". Barros estabelece uma conexão entre o seriado e sua pesquisa etnográfica buscando entender as ambiguidades presentes nas representações de "patroa" e "empregada" e em seus comportamentos como consumidoras.

Ana Lucia Enne vem, desde seu mestrado e doutorado em Antropologia no Museu Nacional da UFRJ, pesquisando os meios de comunicação de massa, em particular a Baixada Fluminense, memória e representação social. Neste artigo, ela vai discutir um programa de televisão - a novela Vale Tudo - e o filme A rede social. A questão ética é o foco do seu trabalho. Partindo da recepção à novela quando de sua exibição pela primeira vez em 1988 e depois em 2011, Enne percebe uma diferença de reação do público em relação aos vilões e suas atitudes. Se, num primeiro momento, foram muito criticados, já no século XXI, suas atitudes e seu comportamento desonesto foram relativizados e de certa forma aceitos, como no caso do filme norte-americano sobre o processo de criação do Facebook e as atitudes do proprietário da rede social.

Julia Schnorr é mestranda em Comunicação Midiática da Universidade Federal de Santa Maria e seu artigo analisou dois grupos de jovens rurais de classes populares: um pertencente a famílias assentadas pelo Movimento dos Trabalhadores Rurais Sem Terra (MST) e o outro ligado ao projeto de Economia Solidária. Seu objetivo foi perceber como este universo se relaciona com o Jornal Nacional (JN) e suas representações do meio rural, do trabalhador do campo e da pobreza. Para eles, fica evidente que a prioridade do telejornal é o mundo urbano e apenas assuntos como o uso de agrotóxico e o agronegócio despertam maior interesse. Outros chamam a atenção para o fato de o MST aparecer sempre na televisão como um movimento violento, principalmente em suas manifestações. $E$ todos são muito críticos em relação à maneira como o $\mathrm{JN}$ apresenta a pobreza no meio rural, sempre a relacionando à miséria e à vulnerabilidade. 
A crônica e sua relação estreita com o universo urbano é o tema abordado por Jeana Santos. Para a pesquisadora doutora em Letras, a crônica é emblemática da experiência moderna e inaugura uma nova perspectiva para a cidade como um lugar de produção de novos sentidos e comportamentos. A partir de algumas crônicas da virada do século no Rio de Janeiro de Machado de Assis e João do Rio, Santos analisa a cidade que traduz o imaginário de uma época. A seu ver, João do Rio é uma figura paradigmática dessa junção entre o flâneur e o jornalista. Ele é aquele que com sua aguda observação irá documentar os tipos urbanos retratando, assim, a rua como essência da modernidade.

O universo de livros de autoajuda é o tema do trabalho de Talita Castro em sua tese de doutorado. Ela busca entender como este gênero de enorme sucesso comercial, no Brasil e no exterior, possui significados tão distintos em contextos diversos como o mundo acadêmico, o editorial e o público em geral. Sua reflexão parte da ideia de que estes livros são definidos pelos intelectuais como negativos, risíveis e pouco sérios. Castro analisou textos e entrevistas de autores de livros considerados de autoajuda e percebeu que os estereótipos neles presentes indicam que é através deles que se pensa esse gênero. A seu ver, a própria pesquisa antropológica sobre este tema acaba sendo vista com estranheza e desprezo. Do contrário, os únicos objetivos dessa investigação seriam: descobrir se os livros deste gênero são "eficazes" e tornam a pesquisadora capaz de escrever um deles e assim enriquecer.

A produção fílmica e as representações nela envolvidas referentes aos jovens e à juventude são temáticas compartilhadas pelos artigos de Janie Pacheco e de César Cundari da Rocha Santos, Lennita Oliveira Ruggi e Marcelo Francisco.

$\mathrm{O}$ texto de Janie K. Pacheco parte da premissa adotada por Dayrel (2003) de que existem jovens específicos, que se 
encontram em contextos específicos, o que significa que não há uma suposta juventude, mas juventudes. Para demonstrar e discutir esse modo de abordar o tema, a autora tece um breve panorama sobre produções fílmicas desde os anos 1950, embora seu foco de análise recaia sobre seis películas produzidas no período entre 2002 e 2011. Para Pacheco, uma vez que a juventude é uma categoria social consolidada e constituída por imagens midiáticas desde as primeiras décadas do século XX, é no cinema que se pode observar o modo como a cultura juvenil se expressa. Nesse sentido, embora as narrativas, na maioria das vezes, tenham como cenário os centros urbanos, as temáticas são diversas: violência e criminalidade, tráfico de drogas, busca por emprego, dificuldades no convívio social, iniciação sexual, relacionamento amoroso, entre outras.

César Santos, Lennita Ruggi e Marcelo Francisco optaram por abordar especificamente filmes sobre high school lançados nos anos 1980, em especial os do roteirista-produtor-diretor John Hughes, considerado nos EUA como pai do gênero. São analisados Gatinhas e Gatões (1984), Clube dos Cinco (1985), Mulher Nota Mil (1985), Curtindo a Vida Adoidado (1986), Garota de Rosa-Shocking (1986) e Alguém Muito Especial (1987). O que se pretende discutir são as formas de sociabilidade escolar presentes nesses filmes, envolvendo jovens entre si e nas relações com adultos. Para os autores, fica claro que, nas produções, a aprendizagem não é tida como relevante, perdendo espaço para temas recorrentes como consumo, popularidade e sexualidade.

Tanto Mercedes Calzado quanto Jimena Massa de algum modo trabalham com a ideia do medo, do risco e a questão de segurança em contextos argentinos distintos. No primeiro caso, relacionadas às imagens trabalhadas em campanhas políticas audiovisuais e, no segundo, a manchetes de jornais relativas à violência sexual. 
Em seu artigo, Calzado analisa as campanhas audiovisuais dos candidatos presidenciais na Argentina a partir do retorno da democracia, abordando os significados da violência e do risco em suas construções imagéticas. Como a autora observa, nas sociedades contemporâneas, a proteção se torna um imperativo categórico de gestão política, uma vez que o risco é percebido como incontrolável e fruto de uma debilidade estatal para lidar com ele. Assim, as campanhas eleitorais apresentam-se como locais onde simultaneamente é possível diagnosticar a construção de tais ameaças à ordem social e apresentar possibilidades de controle do "perigo" pelo Estado. A partir de promessas de campanha, a política surge, então, como um território de sonhos e esperanças.

Já Jimena Massa parte de um caso publicamente conhecido como "o estuprador serial de Córdoba" (Argentina), que teve enorme repercussão na mídia nacional e internacional. A autora mostra a construção social do medo, com ênfase nas retóricas midiáticas sobre a violência e a (in)segurança urbana. Discute, ainda, numa perspectiva de gênero, que a enunciação midiática constrói e amplifica um medo que é, quase sempre, feminino. Nessa narrativa, o estupro é tratado como um sofrimento repentino e como quebra do cotidiano, em que as mulheres são caracterizadas ao mesmo tempo como vítimas e corajosas, e o homem é representado a partir de imagens animalizadas ou patologizadas. A análise dessa construção discursiva permite mostrar também em que medida os imaginários midiáticos configuram práticas que modificam de forma substantiva hábitos e estilos de vida.

Quem também analisa um caso amplamente repercutido nos meios de comunicação de massa é Luciana de Oliveira. A autora apresenta e analisa os discursos sobre desenvolvimento e sustentabilidade presentes numa amostra do debate midiático nacional sobre a instalação da Usina Hidrelétrica de Belo Monte na Amazônia brasileira. Ao 
adotar a perspectiva teórica do "acontecimento" ou do "quase acontecimento", e da ideia de que os discursos "fazem-fazer" e "fazem-falar" - presente em Latour - a autora discute atores e enquadramentos tradutores de modos de entendimento acerca das relações entre natureza-cultura, que se colocam em disputas hegemônicas de sentido.

Finalmente, Silvia Nogueira, em seu artigo, tem como pressuposto o entendimento de que na nossa "sociedade do espetáculo" para entrar no jogo social da exposição midiática é fundamental tornar-se visível. Mais importante que a busca pela visibilidade em si é a administração de visibilidade na qual os jogadores tentam controlar o que e o modo como algo será dado a conhecer. Nesse sentido, a autora apresenta e analisa as estratégias utilizadas pela Secretaria de Comunicação da Presidência da República para a produção de informações sobre o "Brasil", direcionadas a formadores de opinião pública mundial, com o objetivo de influenciar as percepções sobre o país no âmbito internacional. Para isso, utiliza abordagens tanto do campo da Antropologia quanto das Relações Internacionais, numa tentativa de discussão sobre que "Brasil" é esse apresentado pelo governo brasileiro, e as dimensões políticas e culturais estratégicas presentes nesse jogo em que a utilização dos meios de comunicação de massa desempenha papel central.

\section{Referências}

ABU-LUGHOD, L. A interpretação de cultura(s) após a televisão. Cadernos de Antropologia e Imagem, Rio de Janeiro, n.132, p.103129, 2001. .; GINSBURG, F.; LARKIN, B. Media Worlds: anthropo-

logy on new terrains. Berkeley: University of California Press, 2002. 
ADORNO, T.; HORKHEIMER, M. Dialética do esclarecimento. Rio de Janeiro: Jorge Zahar, 1985.

BENJAMIN, W. Obras escolhidas. São Paulo: Brasiliense, 1998.

ECO, Umberto. Apocalípticos e integrados. São Paulo: Perspectiva, 1998.

LEAL, O. F. A leitura social da novela das oito. Petrópolis: Vozes, 1986.

NOGUEIRA, S. G. Facetas do rádio. Uma etnografia das emissoras de Ilhéus (Sul da Bahia). (Tese) Doutorado PPGAS/UFRJ, 2005. (mimeo).

. A construção da notícia em dois jornais cariocas: uma abordagem etnográfica. Dissertação (Mestrado em Antropologia Social), PPGAS/UFRJ, 1998. (mimeo)

PARK, R. A notícia como forma de conhecimento: um capítulo dentro da sociologia do conhecimento. In: BERGER, C.; MAROCCO, B. (Orgs.) A era glacial do jornalismo: teorias sociais da imprensa. Porto Alegre: Sulina, 2008. Vol. 2.

ROCHA, E. Magia e capitalismo. São Paulo: Brasiliense, 1990. . A sociedade do sonho. Rio de Janeiro: Mauad, 1995.

SPITULNIK, D. Anthropology and mass media. Annual Review of Anthropology, n. 22, p. 293-314, 1993. 
SOUZA, C. V. Repórteres e reportagens no jornalismo brasileiro. Rio de Janeiro: Fundação Getúlio Vargas, 2010.

TRAVANCAS, I. O mundo dos jornalistas. 4. ed. São Paulo: Summus Editorial, 1993.

TRAVANCAS, I.; FARIAS, P. (Orgs.). Antropologia e comunicação. Rio de Janeiro: Garamond, 2003. 